\title{
The Role of Nitric Oxide in the Intraocular Pressure Lowering Efficacy of Latanoprostene Bunod: Review of Nonclinical Studies
}

\author{
Megan E. Cavet and Heleen H. DeCory
}

\begin{abstract}
Latanoprostene bunod (LBN) is a topical ophthalmic therapeutic for the reduction of intraocular pressure (IOP) in patients with open-angle glaucoma or ocular hypertension (OHT). LBN is composed of latanoprost acid (LA) linked to a nitric oxide (NO)-donating moiety and is the first NO-releasing prostaglandin analog to be submitted for marketing authorization in the United States. The role of latanoprost in increasing uveoscleral outflow of aqueous humor $(\mathrm{AqH})$ is well established. Herein, we review findings from nonclinical studies, which evaluated the role of NO in the IOP-lowering efficacy of LBN. Pharmacokinetic studies in rabbits and corneal homogenates indicate that LBN is rapidly metabolized to LA and butanediol mononitrate (BDMN). NO is subsequently released by BDMN as shown by increased cyclic guanosine monophosphate (cGMP) levels in (1) the $\mathrm{AqH}$ and iris-ciliary body after administration of LBN in rabbits and in (2) human trabecular meshwork (TM) cells after incubation with LBN. LBN reduced myosin light chain phosphorylation, induced cytoskeletal rearrangement, and decreased resistance to current flow to a greater extent than latanoprost in TM cells, indicating that NO released from LBN elicited TM cell relaxation. LBN also lowered IOP to a greater extent than latanoprost in FP receptor knockout mice, rabbits with transient OHT, glaucomatous dogs, and primates with OHT. Along with results from a Phase 2 clinical study in which treatment with LBN $0.024 \%$ resulted in greater IOP-lowering efficacy than latanoprost $0.005 \%$, these data indicate that LBN has a dual mechanism of action, increasing AqH outflow through both the uveoscleral (using LA) and TM/Schlemm's canal (using NO) pathways.
\end{abstract}

Keywords: nitric oxide, latanoprost, intraocular pressure, trabecular meshwork, ocular hypertension, glaucoma

\section{Introduction}

$\mathbf{E}$ LEVATED INTRAOCULAR PRESSURE (IOP) is considered to be the most important risk factor for the development of glaucoma, an optic neuropathy that affects $\sim 2$ million people in the United States (US) and up to 70 million people worldwide. $^{1,2}$ Large-scale prospective clinical trials have provided evidence that reducing IOP can slow or halt further progression of glaucoma, in addition to delaying disease onset in individuals with ocular hypertension (OHT). ${ }^{3-7}$ Physiological IOP is regulated by a balance in the production of aqueous humor $(\mathrm{AqH})$ in the ciliary body and $\mathrm{AqH}$ outflow. The trabecular meshwork (TM)/Schlemm's canal (conventional) pathway accounts for $60 \%-80 \%$ of outflow while the uveoscleral (nonconventional) pathway accommodates the remainder., 8
The majority of the resistance to $\mathrm{AqH}$ outflow is in the outer most region of the TM, namely the juxtacanalicular tissue (JCT). While the pathological changes leading to elevated IOP in OHT/glaucoma are not completely understood, it is known that increased cell contractility and extracellular matrix deposition result in an overall increased stiffness of the JCT leading to reduced AqH outflow. ${ }^{10-14}$ The resulting increase in IOP may lead to optic nerve fiber dysfunction and retinal ganglion cell death, which are associated with progressive peripheral visual field loss. ${ }^{15}$ Despite the primary role of the TM in AqH outflow, current drug therapies aimed at lowering IOP primarily increase $\mathrm{AqH}$ outflow through the uveoscleral route or by suppressing AqH production. ${ }^{15}$

Latanoprostene bunod (LBN), a novel IOP-lowering drug, is currently under FDA review for the reduction of IOP in

Pharmaceutical Medical Affairs, Bausch + Lomb, Rochester, New York.

(C) Megan E. Cavet and Heleen H. DeCory, 2018; Published by Mary Ann Liebert, Inc. This article is available under the Creative Commons License CC-BY-NC (http://creativecommons.org/licenses/by-nc/4.0). This license permits non-commercial use, distribution and reproduction in any medium, provided the original work is properly cited. Permission only needs to be obtained for commercial use and can be done via RightsLink. 
patients with open-angle glaucoma (OAG) or OHT. LBN is a nitric oxide (NO)-donating prostaglandin $\mathrm{F} 2 \alpha$ analog that is metabolized in situ to latanoprost acid (LA) and butanediol mononitrate (BDMN), a NO-donating moiety (Fig. 1). BDMN then releases 1,4-butanediol, an inactive metabolite, and the signaling molecule NO. ${ }^{16}$ Published data suggest that LA and NO released from LBN both contribute to the IOP-lowering efficacy of LBN by increasing AqH outflow through the uveoscleral and TM/Schlemm's canal pathways, respectively. The action of LA on the uveoscleral (nonconventional) pathway has been studied extensively and is well established. Briefly, LA is known to bind to the prostanoid FP receptor in the ciliary muscle leading to an upregulation of matrix metalloproteinases. Over time this results in a remodeling of the extracellular matrices in the ciliary body resulting in enlarged spaces within the ciliary muscle bundles and increased $\mathrm{AqH}$ outflow. ${ }^{8,17,18}$ In addition, LA is thought to mediate an initial reduction of IOP through ciliary muscle relaxation. ${ }^{8,17,18}$

$\mathrm{NO}$ is an endogenous signaling molecule generated by the nitric oxide synthase (NOS) family of enzymes from Larginine. ${ }^{19-21}$ NO elicits a downstream signaling cascade through activation of the soluble guanylyl cyclase (sGC) enzyme, which is a heterodimer existing as either $\mathrm{sGC} \alpha_{1} \beta_{1}$ (sGC-1) or sGC $\alpha_{2} \beta_{1}$ (sGC-2) in vivo. ${ }^{22} \mathrm{NO}$ has an array of functions throughout the body, including roles in vascular homeostasis, regulation of pulmonary vasomotor tone, neuronal physiology, and immune regulation. ${ }^{19-21}$

In the eye NO plays an important role in physiological IOP regulation, as illustrated by studies in which mice overexpressing endothelial (e)NOS were shown to have lowered IOP, while mice lacking eNOS were shown to have elevated IOP compared to wild-type or transgenic control animals. ${ }^{23,24}$ Further studies in eNOS overexpressing or eNOS knockout enucleated mouse eyes, in cultured Schlemm's canal cells and in ex vivo anterior segment organ culture perfusion models, indicated that endogenous NO lowers IOP by facilitating TM/Schlemm's canal outflow. ${ }^{23-28}$ Studies have also shown that impaired NO signaling may contribute to IOP dysregulation in OAG. Mice deficient in the $\alpha 1$ subunit of sGC-1 exhibited an elevation in IOP as they aged from 19 to 37 weeks, in contrast to wild-type mice in which IOP was unchanged over time. sGC-1-deficient mice also had decreased $\mathrm{AqH}$ outflow and exhibited both optic neuropathy and retinal vascular dysfunction. ${ }^{29}$

In humans, NO metabolites were found to be reduced in the $\mathrm{AqH}$, as well as the plasma of glaucomatous patients, and NOS levels were found to be decreased in ocular tissue isolated from primary OAG (POAG) donor eyes, including the TM and Schlemm's canal. ${ }^{30-32}$ In addition, serum levels of 2 dimethylated isomeric derivatives of L-arginine, which act as endogenous NOS inhibitors, were found to be elevated in patients with advanced glaucoma. ${ }^{33}$ Polymorphisms in the NOS3 gene, which encodes eNOS, have been associated with POAG, and these polymorphisms appear to be impacted by sex and reproductive hormones. ${ }^{34-36}$ In a study of more than a 1,000 glaucoma patients, higher dietary intake of nitrate, a precursor to NO, was associated with a lower POAG risk, particularly POAG associated with early paracentral visual field loss. ${ }^{37}$ Since early paracentral visual field loss is thought to be caused by dysfunction of blood flow autoregulation, this study suggests that NO plays a key role not only in IOP regulation but also in regulation of<smiles>O=C(O)CCC/C=C/C[C@H]1[C@@H](O)C[C@H](O)[C@@H]1CC[C@H](O)CCc1ccccc1</smiles>

FIG. 1. Metabolism of latanoprostene bunod to latanoprost acid and nitric oxide. Following topical ocular administration, latanoprostene bunod undergoes carboxyl ester hydrolysis to latanoprost acid (1) and butanediol mononitrate, which is subsequently reduced to 1,4-butanediol and nitric oxide (2). Reproduced with permission from Kawase et al. ${ }^{76}$ 
ocular blood flow. ${ }^{38}$ Taken together these and other studies underscore the role of endogenous NO in physiological IOP regulation and its dysregulation in glaucoma.

Since endogenous NO plays a key role in IOP regulation, exogenous NO donors may have therapeutic value as IOPlowering agents. Indeed, studies have demonstrated that NO donors decrease IOP by increasing conventional $\mathrm{AqH}$ outflow, mediated by a relaxation of the TM cells, and also perhaps an increase in the permeability of the Schlemm's canal. $^{25,26,28,39-46}$ At the cellular level, relaxation of the TM is thought to be analogous to the well-characterized NO/ sGC/cyclic guanosine monophosphate (cGMP) signaling cascade delineated in blood vessels. ${ }^{47}$ Schlemm's canal cells, similar to endothelial cells lining the blood vessels, increase endogenous NO production in response to shear stress supporting a role for NO in IOP homeostasis. ${ }^{47,48} \mathrm{NO}$ can diffuse into neighboring cells, namely the vascular smooth muscle cells in the blood vessel and TM cells in the eye, where it binds to and activates the sGC enzyme, resulting in increased production of cGMP and activation of protein kinase $\mathrm{G}$ (PKG). ${ }^{22,26,42,45-47}$ PKG activation, in turn, leads to inhibition of Rho A and thus Rho kinase, activation of $\mathrm{K}^{+}$ channels, inhibition of L-type $\mathrm{Ca}^{2+}$ channels, and increased uptake of calcium into the sarcoplasmic reticulum. ${ }^{27,45,47,49,50}$ These signaling pathways, together with the direct action of $\mathrm{PKG}$, result in activation of myosin light chain phosphatase, while lower intracellular $\mathrm{Ca}^{2+}$ levels result in inhibition of myosin light chain kinase. Subsequent dephosphorylation of the regulatory light chain of myosin prevents actin-myosin interaction, promoting cell relaxation. ${ }^{39,47,49-52}$ Ultimately this leads to a widening of the intercellular spaces in the juxtacanalicular TM and Schlemm's canal, thus facilitating conventional AqH outflow. 49,50,53

Therefore, published data indicate that LBN lowers IOP using a dual mechanism of action, with LA primarily increasing $\mathrm{AqH}$ outflow through the uveoscleral pathway and NO increasing AqH outflow through the TM/Schlemm's canal pathway (Fig. 2). Targeting the conventional outflow pathway with $\mathrm{NO}$ is advantageous since this is the primary outflow pathway under normal conditions and the site of impaired

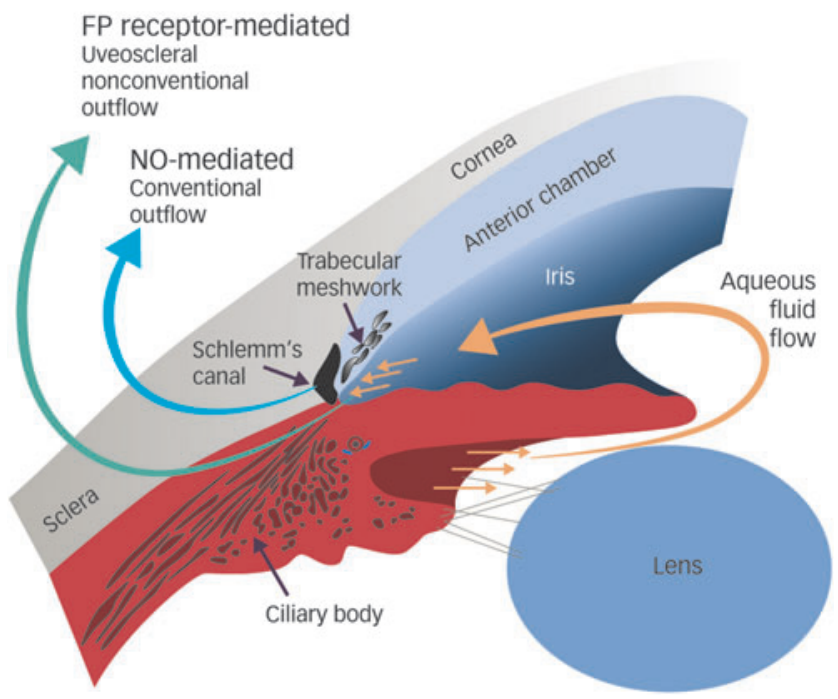

FIG. 2. Dual mechanism of action of latanoprostene Bunod. Reproduced with permission from touchOPHTHALMOLOGY from Fig. 2, Weinreb et al. ${ }^{58}$ drainage leading to the elevation of IOP and resulting optic nerve head damage in glaucoma. ${ }^{10,11}$ In addition, as previously indicated, markers for $\mathrm{NO}$ are reported to be at lower levels in the anterior tissues of glaucomatous patients, suggesting that NO signaling pathways may be impaired in glaucoma. ${ }^{30-32}$ Restoring $\mathrm{AqH}$ flow to the conventional pathway will not only lower IOP but also may minimize IOP fluctuations, another risk factor in the progression of glaucoma. ${ }^{12,54-56}$

Currently, the NO-donating compounds nitroglycerin, isosorbide mononitrate, and sodium nitroprusside are used clinically in the US, with a systemic route of administration for cardiovascular conditions such as angina and acute hypertension. ${ }^{57}$ LBN ophthalmic solution $0.024 \%$ is the first NOdonating topical ophthalmic therapy to be submitted for marketing authorization in the US for lowering of IOP. This review is focused on the nonclinical studies supporting the NDA submission for LBN 0.024\%. Pharmacokinetic (PK) studies, which demonstrated the rapid metabolism of LBN to LA and BDMN followed by release of NO, are briefly reviewed, followed by a comprehensive summary of in vitro and in vivo pharmacodynamic studies which were performed to demonstrate both the IOP-lowering efficacy of and the contribution of NO to the dual mechanism of action of LBN. These studies provided the basis for the clinical development program for LBN, recently reviewed elsewhere. ${ }^{58,59}$

\section{Nonclinical Pharmacokinetic Studies}

LBN PK studies focused on evaluating the in vitro metabolism and ocular distribution of the metabolite LA.

\section{LA levels in corneal homogenates}

An in vitro study compared the ester hydrolysis of LBN and latanoprost. Rabbit and primate corneal homogenates were incubated with either LBN or latanoprost, and the formation of LA was measured using liquid chromatography tandem-mass spectrometry (LC-MS-MS). Both drugs were rapidly metabolized to yield LA in the corneal homogenate, in agreement with the known high esterase levels present in cornea. ${ }^{60}$ The hydrolysis of LBN (half-life of 0.05 and $0.40 \mathrm{~min}$ in rabbit and primate corneal homogenate, respectively) appeared to be faster than that for latanoprost (half-life of 0.28 and $5.2 \mathrm{~min}$ in rabbit and primate corneal homogenate, respectively; Data on file, Bausch and Lomb, Inc.) and was associated with a corresponding increase in LA levels. Additional studies were performed in rabbit $\mathrm{AqH}$ and primate and human plasma, with similar results (Data on file, Bausch and Lomb, Inc.).

\section{LA levels in ocular tissues}

Levels of LA in the cornea, $\mathrm{AqH}$, and iris-ciliary body (ICB) were measured after a single $30-\mu \mathrm{L}$ topical ocular administration of either $0.012 \% \mathrm{LBN}$ or the equimolar latanoprost dose $(0.01 \%)$ in each eye of male Dutch Belted rabbits $(n=16)$ and cynomolgus monkeys $(n=8) .{ }^{16}$ Animals were euthanized at $0.5,1,3$, and $6 \mathrm{~h}$ after dosing, and the cornea, $\mathrm{AqH}$, and ICB were harvested for determination of LBN (in primates only) and LA concentrations by LC-MSMS. In both species, concentrations of LA were $>15$-fold higher in the cornea than in the AqH and ICB after topical administration of either LBN or latanoprost. Instillation of $\mathrm{LBN}$ resulted in a similar distribution of LA into the cornea, 
$\mathrm{AqH}$, and ICB compared to that seen with latanoprost. The maximum concentration $\left(\mathrm{C}_{\max }\right)$ of LA after administration of LBN or LA was observed at $0.5-1 \mathrm{~h}$ postdose in all tissues. Thereafter, LA concentrations decreased with a halflife of 1.8-4.6 h for LBN and 1.1-3.0 h for latanoprost. No LBN was detected at any time point in the primate study in any of the tissues evaluated, consistent with its rapid ester hydrolysis. These data suggest that LBN is rapidly distributed into ocular tissues following topical instillation, and that, of the tissues evaluated, the cornea appears to be a primary site of metabolism of LBN to LA.

\section{cGMP levels in ocular tissues}

Measuring NO levels in vivo is technically challenging due to the short half-life ( $\sim 2 \mathrm{~s}$ in extravascular tissue) and high diffusibility of the molecule. ${ }^{61}$ To confirm that NO is released from BDMN, levels of the downstream signaling molecule cGMP were measured in the $\mathrm{AqH}$ and ICB of rabbits following topical ocular administration of $\mathrm{LBN} .{ }^{16}$ In these experiments, cGMP in the $\mathrm{AqH}$ is presumed released from the surrounding ocular tissues by membrane transporters. $^{52,62,63}$ Briefly, male Dutch Belted rabbits $(n=4)$ received a single $50-\mu \mathrm{L}$ topical instillation of LBN $0.036 \%$ or the equimolar dose of latanoprost $(0.03 \%)$ in each eye. Animals were euthanized at $1 \mathrm{~h}$ postdose and the $\mathrm{AqH}$ and ICB were harvested for determination of cGMP concentrations using a cGMP enzyme immunoassay. Untreated animals $(n=4)$ were also euthanized to determine basal cGMP levels in these tissues. Topical dosing of LBN resulted in an increase in mean (standard deviation) cGMP levels from 3 (1) to $122(28) \mathrm{ng} / \mathrm{mL}$ in the $\mathrm{AqH}$ and from 10 (2) to $48(26) \mathrm{ng} / \mathrm{g}$ in the ICB $(P<0.05$ for both vs. basal levels). In contrast, topical dosing of latanoprost $0.03 \%$ did not result in an increase in cGMP detected in either the $\mathrm{AqH}$ or the ICB. Data in the literature describing the metabolism of other BDMN-releasing compounds indicate that ester hydrolysis must occur before the release of NO from BDMN. ${ }^{64}$ Therefore, detection of elevated cGMP in the $\mathrm{AqH}$ and ICB following topical instillation of LBN suggests that LBN is hydrolyzed to LA and BDMN and that the $\mathrm{NO}$ subsequently released from BDMN reaches the anterior ocular tissues in sufficient levels to activate the $\mathrm{NO} / \mathrm{sGC} /$ GC pathway.

\section{Nonclinical Pharmacodynamic Studies}

The contribution of NO to the IOP-lowering efficacy of LBN was evaluated in TM cells in vitro and in 4 animal models. Cavet et al. determined the effect of LBN versus the equimolar concentration of latanoprost on human TM cell relaxation. ${ }^{51}$ Saeki et al. compared the IOP lowering effect of LBN to an equimolar concentration of latanoprost in wild-type and prostanoid FP receptor knockout (FPKO) mice. ${ }^{65}$ Krauss et al. evaluated the IOP-lowering effect of LBN in comparison to latanoprost in 3 animal models of OHT or OAG, namely rabbits with saline-induced OHT, beagle dogs with inherited primary $\mathrm{OAG}$, and nonhuman primates with laser-induced OHT. ${ }^{16}$

\section{Effect of $L B N$ on human TM cells}

$N O$-mediated cGMP stimulation. The ability of LBN to increase cGMP was demonstrated in primary human TM

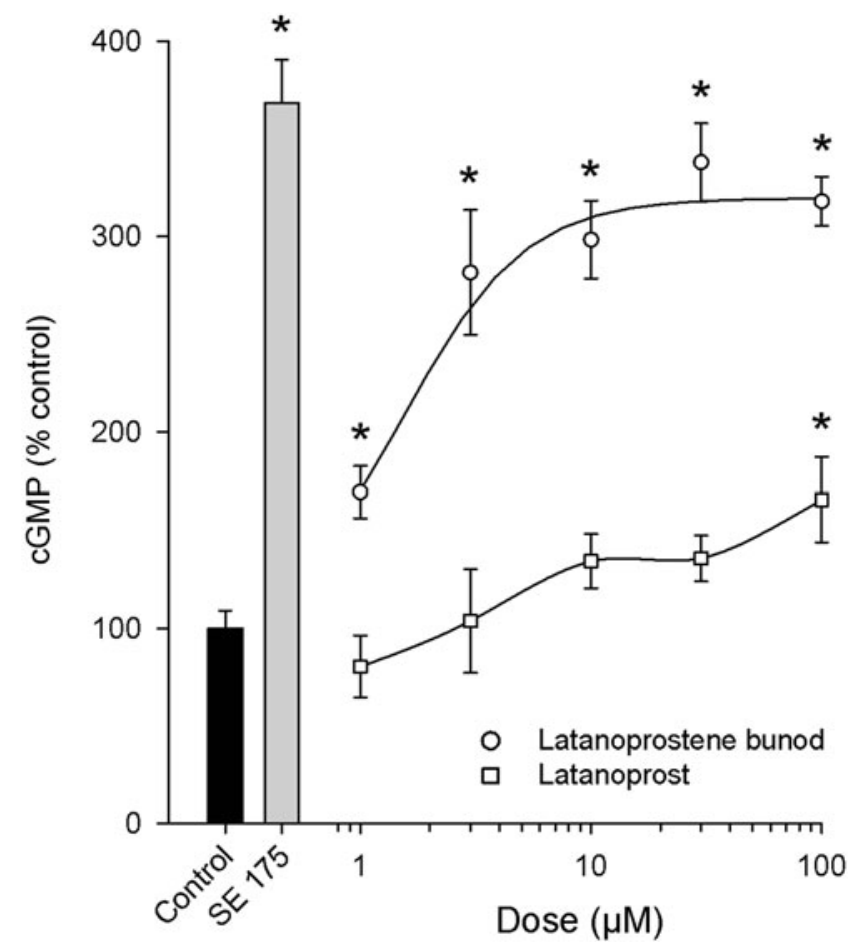

FIG. 3. Effect of LBN on cGMP levels in trabecular meshwork cells. Human trabecular meshwork cells were treated with increasing doses of $\mathrm{LBN}$ or latanoprost, or the $\mathrm{NO}$ donor SE $175(100 \mu \mathrm{M})$ for $30 \mathrm{~min}$. Cell lysates were assayed for cGMP levels using an enzyme immunoassay. $n=6-24$ from 4 independent experiments, LBN line is data fit to a 4 parameter logistic equation, line for latanoprost is interpolation between the data points. Data $=$ mean \pm standard error of the mean. $* P<0.05$ versus control. Adapted with permission from Cavet et al. ${ }^{51}$ cGMP, cyclic guanosine monophosphate; LBN, latanoprostene bunod.

cells in vitro. ${ }^{51}$ LBN elicited a dose-dependent increase in cGMP levels, as determined by ELISA (Fig. 3). The half maximal effective concentration [standard error of the mean (SEM)] for LBN for induction of TM cell cGMP levels was $1.54(0.33) \mu \mathrm{M}$, and the mean (SEM) maximal effect was a $320(13 \%)$ increase in cGMP over control. LBN induced cGMP production was sensitive to inhibition with the specific sGC inhibitor, $1 \mathrm{H}-[1,2,4]$ oxadiazolo[4,3-a]quinoxalin1-one. In contrast, there was no effect of latanoprost on cGMP levels, except for at the highest concentration tested $(100 \mu \mathrm{M})$, when a small but significant increase was observed (Fig. 3). A previous study also showed that prostaglandin analogues, including latanoprost increased cGMP in TM cells, although to a much lesser extent than the NO donor sodium nitroprusside, by an as yet undefined mechanism. ${ }^{66}$

NO-mediated cell relaxation. As described above, $\mathrm{sGC/}$ cGMP activation by NO is known to trigger multiple cellular signaling pathways, which result in myosin light chain (MLC) dephosphorylation, cytoskeletal rearrangement through disassociation of actin-myosin interactions and, thus, cell relaxation. ${ }^{47}$ The ability of LBN to increase TM cell relaxation was investigated using 3 separate assays of actin-myosin cytoskeleton dynamics, namely MLC phosphorylation, filamentous (F)-actin stress fiber and focal adhesion distribution, and electrical cell substrate impedance 
sensing (ECIS). ${ }^{51}$ In these assays, TM cells were induced to contract using endothelin-1 (ET-1), a known pathogenic mediator of glaucoma, ${ }^{67,68}$ and the effect of LBN was compared to that of latanoprost over an equivalent concentration range. The ability of LBN and latanoprost to decrease MLC phosphorylation was determined by Western blotting using antibodies to both the Ser 19 and Thr 18 MLC-2 phosphorylation sites. ${ }^{51}$ Results showed that LBN significantly reduced ET-1 induced MLC phosphorylation at multiple concentrations. In contrast, latanoprost increased MLC phosphorylation at low doses $(10 \mu \mathrm{M})$ and significantly reduced ET-1 induced MLC phosphorylation relative to ET-1 alone only at the highest dose tested $(60 \mu \mathrm{M})$. To evaluate the effect of LBN and latanoprost on ET-1-induced actin filament and focal adhesion formation, human TM cells were incubated with ET-1 and LBN or latanoprost and stained for F-actin using fluorescently labeled phalloidin and for focal adhesions using vinculin antibody. The cells were then imaged using confocal microscopy. ${ }^{51}$ Pretreatment of TM cells with LBN dramatically reduced ET-1-induced stress fibers and vinculin staining, while there was minimal effect with an equimolar concentration of latanoprost (Fig. 4). Finally, the effect of LBN and latanoprost was evaluated quantitatively by measuring change in resistance

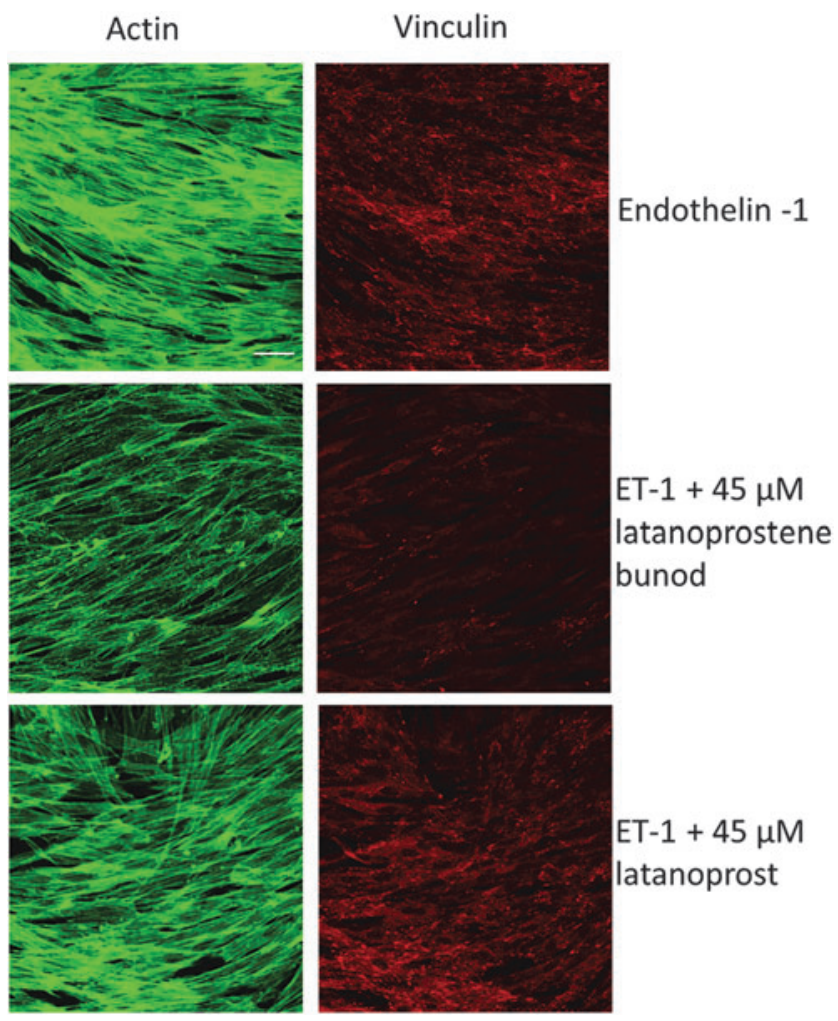

FIG. 4. Effect of LBN on actin and vinculin distribution in trabecular meshwork cells. Human trabecular meshwork cells were treated with ET-1 \pm LBN $(45 \mu \mathrm{M})$,] or latanoprost $(45 \mu \mathrm{M})$ for $1 \mathrm{~h}$. Cells were fixed and stained for actin (green; using phalloidin) and focal adhesions (red; using vinculin monoclonal antibody). Left column is F-actin, right column is vinculin. Images are best representative of 4 individual experiments. Scale bar (upper left hand panel) $=20 \mu \mathrm{M}$. Adapted with permission from Cavet et al. ${ }^{51}$ ET-1, endothelin-1; LBN, latanoprostene bunod. to current flow in real time using ECIS, in which the resistance to current flow across the cells can be used as an indicator of cell stiffness or contractility. ${ }^{51,69}$ Briefly, cells were treated with ET-1 or ET-1 plus either LBN or latanoprost for $120 \mathrm{~min}$. While both drugs reduced ET-1 induced resistance to current flow after $10 \mathrm{~min}$ of incubation, the effect of LBN was significantly greater compared with an equimolar concentration of latanoprost from 30 to $120 \mathrm{~min}$ $(P<0.05$ vs. latanoprost). For example, after $80 \mathrm{~min}$, the resistance in ET-1+LBN-treated cells was equivalent to baseline (pre-ET-1) levels (98.5\% reduction vs. ET-1 alone), while latanoprost only reduced resistance by $53.6 \%$ versus ET-1 alone. Of note, further studies demonstrated that incubation of TM cells with a combination of latanoprost and the NO donor SE 175 elicited a significantly greater reduction in ET-1 induced resistance compared to sum of the effects of the individual drugs, suggesting a synergistic interaction between latanoprost and the NO released by SE 175 on TM cell relaxation. Overall, these data indicate that the NO-donating moiety of LBN likely mediates IOP-lowering by relaxation of the TM, allowing increased aqueous outflow through the conventional pathway.

\section{Effect of $\angle B N$ on IOP in animal models}

IOP lowering in wild-type and prostanoid FP receptor knockout mice. In the first study, wild-type C57BL/6J mice were instilled with $3 \mu \mathrm{L} \mathrm{LBN} 0.006 \%$ or latanoprost $0.005 \%$ in 1 eye, and the contralateral eye was left untreated ( $n=8$ animals/group). IOP was measured under anesthesia at baseline and at 1,2,3, and $6 \mathrm{~h}$ after dosing in anesthetized mice using a microneedle placed in the anterior chamber and connected to a pressure transducer. There was no significant difference between LBN $0.006 \%$ and latanoprost $0.005 \%$ in the IOP response versus time profiles in wild-type mice, although a trend toward greater IOP-lowering with LBN $0.006 \%$ was observed (Table 1$).{ }^{65}$ In the second study, FPKO mice were instilled with $3 \mu \mathrm{L} \mathrm{LBN} 0.006 \%$ in 1 eye. IOP was measured at $3 \mathrm{~h}$ postinstillation and compared to IOP in either the contralateral eye instilled with saline measured concurrently ( $n=8$ animals/group) or the same eye instilled with saline measured 2 weeks later $(n=7$ animals/group). In FPKO mice there was a significant reduction in IOP at the 3-h time point comparing to IOP either in the contralateral eye or in the same eye 2 weeks later (Table 1; $P \leq 0.036) .{ }^{65}$ Since FPKO mice are insensitive to latanoprost, ${ }^{70,71}$ the IOP-lowering effect observed with LBN appears to be due to the action of $\mathrm{NO}$ on the conventional outflow pathway.

IOP lowering in transiently ocular hypertensive rabbits. New Zealand White rabbits, reported to be insensitive to the IOP-lowering effect of latanoprost, ${ }^{72,73}$ were anesthetized, and the vitreous humor of both eyes was injected with $0.1 \mathrm{~mL}$ hypertonic saline to induce transient OHT. ${ }^{16}$ Immediately after the saline injection, eyes were instilled with $50 \mu \mathrm{L} \mathrm{LBN} 0.036 \%(n=9)$, latanoprost $0.030 \%(n=9)$, or vehicle $(n=6)$. IOP was determined using a Tono-Pen before intravitreal saline injection (baseline) and 0.5, 1, 1.5, 3 , and $5 \mathrm{~h}$ thereafter. Injection of saline led to a rapid IOP elevation after $0.5 \mathrm{~h}$ in vehicle-treated eyes. The IOP remained elevated for an additional hour and then declined to baseline over the following $4.5 \mathrm{~h}$. Instillation of LBN $0.036 \%$ 
TABle 1. EFfect of Latanoprostene Bunod on Intraocular Pressure LoWering In WiLd-Type AND FP RECEPTOR KNOCKOUt Mice

\begin{tabular}{llcl}
\hline & & & $\begin{array}{l}\text { IOP lowering } \\
\text { 3h postdosing, } \\
\text { Mouse strain }\end{array}$ \\
\hline Treatment & $\mathrm{N}$ & $\begin{array}{l}\text { mean mean } \\
(\text { SD }\end{array}$ \\
WT & LBN $0.006 \%$ & 8 & $-4.45^{\mathrm{a}}$ \\
FPKO & Latanoprost $0.005 \%$ & 8 & $-3.97^{\mathrm{a}}$ \\
FPKO & LBN $0.006 \%$ & 8 & $-0.45(0.45)^{\mathrm{a}, *}$ \\
\hline
\end{tabular}

${ }^{\mathrm{a} C}$ Compared to IOP measured in the saline-treated contralateral eye.

${ }^{\mathrm{b}}$ Compared to IOP measured in the same saline-treated eye 2 weeks later.

$* P \leq 0.036$ versus comparator.

FPKO, prostanoid FP receptor knockout; IOP, intraocular pressure; LBN, latanoprostene bunod; SD, standard deviation; WT, wild type.

attenuated the saline-induced IOP elevation throughout the postinstillation period $[P<0.05$ vs. vehicle, based on areaunder-the-curve (AUC) analysis]. A maximal decrease in mean (SEM) IOP of 13.5 (2.0) $\mathrm{mm} \mathrm{Hg}$ (30\% reduction) was observed between 0.5 and $1.5 \mathrm{~h}$ post saline injection (Fig. 5). In contrast, instillation of latanoprost at the equimolar concentration of $0.030 \%$ had no effect on saline-induced IOP elevation ( $P=$ NS vs. vehicle based on AUC analysis). ${ }^{16}$

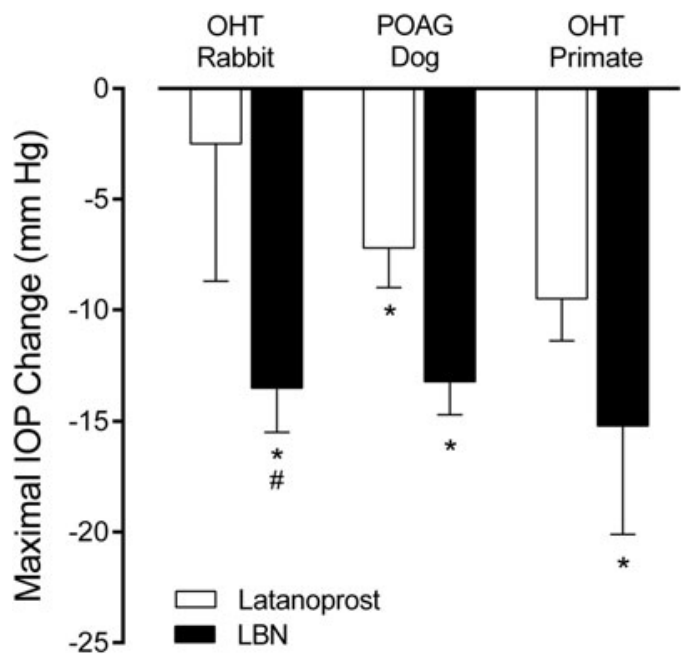

FIG. 5. IOP lowering efficacy of $\mathrm{LBN}$ and latanoprost in ocular hypertensive rabbits, glaucomatous dogs, and ocular hypertensive nonhuman primates. Rabbits with transient OHT were administered topical ocular LBN $(0.036 \%)$ or latanoprost $(0.030 \%)$. Dogs with glaucoma or ocular hypertensive primates were administered topical ocular 1 . LBN $(0.036 \%$ in dogs; $0.030 \%$ in primates) or respective vehicle and 2. latanoprost $(0.030 \%)$ or respective vehicle. Maximal IOP change is the change versus vehicle (rabbits) or change from baseline (dogs and primates). Data are presented as mean (standard error of the mean); $* P<0.05$ versus respective vehicle, ${ }^{\#} P<0.05$ versus latanoprost (statistical comparison to latanoprost performed in rabbits only). Data from Krauss et al. ${ }^{16}$ IOP, intraocular pressure; LBN, latanoprostene bunod; OHT, ocular hypertension. POAG, primary open-angle glaucoma.
IOP-lowering in glaucomatous dogs. Ocular hypertensive beagle dogs with naturally occurring moderate primary OAG were treated with either a $50-\mu \mathrm{L}$ instillation of $\mathrm{LBN}$ $0.036 \%$ or latanoprost $0.030 \%$ in 1 eye ( $n=6$ per treatment), while the contralateral eye was treated with vehicle. ${ }^{16}$ IOP was measured with a Tono-Pen at baseline and at 1, 2, 3, 4, and $6 \mathrm{~h}$ following instillation of the study treatments. LBN $0.036 \%$ treatment resulted in significantly reduced IOP compared to vehicle beginning at $1 \mathrm{~h}$ postinstillation and maintained through $6 \mathrm{~h}(P<0.05$ for all $)$. While latanoprost $0.030 \%$ also lowered IOP compared to vehicle, the reduction was not as robust as that observed with LBN $0.036 \%$ and was significantly greater than vehicle only at the 3-, 4-, and $6-\mathrm{h}$ postinstillation time points $(P<0.05$ for each) suggesting a slower onset of action. Mean (SEM) maximal IOP reduction from baseline was 13.2 (1.5) $\mathrm{mm} \mathrm{Hg} \mathrm{(44 \% )} \mathrm{in}$ LBN-treated eyes at the $2 \mathrm{~h}$ postinstillation time point. In contrast, a maximal IOP lowering of 7.1 (1.8) $\mathrm{mm} \mathrm{Hg}$ or $27 \%$ from baseline occurred at $6 \mathrm{~h}$ in latanoprost-treated eyes (Fig. 5). ${ }^{16}$

IOP-lowering in primates with laser-induced OHT. Cynomolgus monkeys $(n=8)$ with OHT in the left eye, induced by laser photocoagulation of the TM, were randomized to masked treatment with either a $30-\mu \mathrm{L}$ instillation of active treatment (LBN or latanoprost) or a $30-\mu \mathrm{L}$ instillation of the corresponding vehicle. After 3 days animals were crossed over to the alternate treatment. ${ }^{16}$ IOP was measured in anesthetized eyes of conscious animals at baseline and at multiple time points $1-6 \mathrm{~h}$ post study treatment using a pneumatonometer. There was no significant IOP-lowering effect with the lowest dose of either LBN or latanoprost tested $(0.012 \%$ and $0.010 \%$, respectively). However, LBN $0.03 \%$ lowered mean (SEM) IOP by 15.2 (4.9) $\mathrm{mm} \mathrm{Hg}$ or $31 \%$ from baseline $(P<0.05$ vs. vehicle $)$, In contrast, latanoprost $0.03 \%$ was without significant effect. The highest dose of LBN tested, $0.12 \%$, lowered IOP by 13.5 (3.0) $\mathrm{mm}$ $\mathrm{Hg}$ or $35 \%$ from baseline $(P<0.05$ vs. vehicle). The equimolar dose of latanoprost $(0.10 \%)$ also resulted in a significant reduction in IOP, although to a lesser extent than that observed with LBN $0.12 \%$. IOP lowering with latanoprost $0.10 \%$ was $11.9(3.8) \mathrm{mm} \mathrm{Hg}$ or $25.8 \%$ from baseline $(P<0.05$ vs. vehicle $)$.

Therefore, LBN lowers IOP to a greater extent than the equimolar concentration of LA in multiple animal models, indicating that both active moieties (LA and NO) contribute to the efficacy of the drug, with IOP lowering detected at the earliest time point measured $(1 \mathrm{~h})$ and maintained for at least $6 \mathrm{~h}$. Onset of IOP-lowering activity in the animal models was consistent with detection of cGMP in rabbit AqH and ICB, which was measured at $1 \mathrm{~h}$ after topical administration. ${ }^{16}$

\section{Summary}

The nonclinical PK and PD studies on LBN described herein provided the basis for the clinical development program of LBN $0.024 \%$ ophthalmic solution for the reduction of IOP in subjects with OAG or OHT. These studies demonstrated that on topical ocular administration, LBN releases the 2 active moieties LA and NO, which each contribute to the IOP-lowering efficacy of LBN. The ability of LBN to increase levels of the NO second messenger cGMP through activation of sGC was demonstrated in the 
anterior segment tissues after topical administration of LBN to rabbits eyes and in primary human TM cells in vitro. ${ }^{16,51}$ In vitro studies also showed that $\mathrm{LBN}$ mediates $\mathrm{TM}$ cell relaxation to a significantly greater extent than the equimolar concentration of latanoprost suggesting that NO release from BDMN mediates IOP lowering through an increase in conventional outflow. ${ }^{51}$ Greater IOP lowering of LBN over equimolar latanoprost was shown in 4 different animal models (FP receptor knockout mice, transiently ocular hypertensive rabbits, glaucomatous dogs, and laser-induced ocular hypertensive primates $)^{16,65}$ providing evidence for a contribution of both active moieties to the IOP-lowering efficacy of the drug. These data suggest that, in keeping with other NO donors, ${ }^{25,28,39-44}$ LBN may mediate its additional IOP-lowering effects in vivo by facilitating aqueous outflow through the TM. These nonclinical findings were subsequently corroborated by a dose-ranging Phase 2 clinical study (VOYAGER), which showed that LBN $0.024 \%$ resulted in greater IOP-lowering than latanoprost $0.005 \%{ }^{74}$ As latanoprost has been reported to reach its maximal IOP-lowering effect at a concentration of $0.005 \%,{ }^{75}$ the additional IOP-lowering with LBN $0.024 \%$ was attributed to the action of NO. As illustrated in Figure 2, collectively, these data support the concept that LBN has a dual mode of action, targeting both the TM/Schlemm's canal (conventional) and the uveoscleral (nonconventional) $\mathrm{AqH}$ outflow pathways to lower IOP.

\section{Author Disclosure Statement}

No competing financial interests exist.

\section{References}

1. Friedman, D.S., Wolfs, R.C., O’Colmain, B.J., Klein, B.E., Taylor, H.R., West, S., Leske, M.C., Mitchell, P., Congdon, N., and Kempen, J. Prevalence of open-angle glaucoma among adults in the United States. Arch. Ophthalmol. 122: 532-538, 2004.

2. Quigley, H.A., and Broman, A.T. The number of people with glaucoma worldwide in 2010 and 2020. Br. J. Ophthalmol. 90:262-267, 2006.

3. Sommer, A., Tielsch, J.M., Katz, J., Quigley, H.A., Gottsch, J.D., Javitt, J., and Singh, K. Relationship between intraocular pressure and primary open angle glaucoma among white and black Americans. The Baltimore Eye Survey. Arch. Ophthalmol. 109:1090-1095, 1991.

4. Kass, M.A., Heuer, D.K., Higginbotham, E.J., Johnson, C.A., Keltner, J.L., Miller, J.P., Parrish, R.K., 2nd, Wilson, M.R., and Gordon, M.O. The Ocular Hypertension Treatment Study: a randomized trial determines that topical ocular hypotensive medication delays or prevents the onset of primary open-angle glaucoma. Arch. Ophthalmol. 120:701-713, 2002; discussion 829-830.

5. The Advanced Glaucoma Intervention Study (AGIS): 7. The relationship between control of intraocular pressure and visual field deterioration. The AGIS Investigators. Am. J. Ophthalmol. 130:429-440, 2000.

6. Heijl, A., Leske, M.C., Bengtsson, B., Hyman, L., and Hussein, M. Reduction of intraocular pressure and glaucoma progression: results from the Early Manifest Glaucoma Trial. Arch. Ophthalmol. 120:1268-1279, 2002.

7. Garway-Heath, D.F., Crabb, D.P., Bunce, C., Lascaratos, G., Amalfitano, F., Anand, N., Azuara-Blanco, A., Bourne, R.R., Broadway, D.C., Cunliffe, I.A., Diamond, J.P., Fraser,
S.G., Ho, T.A., Martin, K.R., McNaught, A.I., Negi, A., Patel, K., Russell, R.A., Shah, A., Spry, P.G., Suzuki, K., White, E.T., Wormald, R.P., Xing, W., and Zeyen, T.G. Latanoprost for open-angle glaucoma (UKGTS): a randomised, multicentre, placebo-controlled trial. Lancet. 385: 1295-1304, 2015.

8. Winkler, N.S., and Fautsch, M.P. Effects of prostaglandin analogues on aqueous humor outflow pathways. J. Ocul. Pharmacol. Ther. 30:102-109, 2014.

9. Alm, A., and Nilsson, S.F. Uveoscleral outflow-a review. Exp. Eye Res. 88:760-768, 2009.

10. Stamer, W.D., and Acott, T.S. Current understanding of conventional outflow dysfunction in glaucoma. Curr. Opin. Ophthalmol. 23:135-143, 2012.

11. Tamm, E.R., Braunger, B.M., and Fuchshofer, R. Intraocular pressure and the mechanisms involved in resistance of the aqueous humor flow in the trabecular meshwork outflow pathways. Prog. Mol. Biol. Transl. Sci. 134:301-314, 2015.

12. Stamer, W.D. The cell and molecular biology of glaucoma: mechanisms in the conventional outflow pathway. Invest. Ophthalmol. Vis. Sci. 53:2470-2472, 2012.

13. Wang, K., Read, A.T., Sulchek, T., and Ethier, C.R. Trabecular meshwork stiffness in glaucoma. Exp. Eye Res. 2016 (in press).

14. Braunger, B.M., Fuchshofer, R., and Tamm, E.R. The aqueous humor outflow pathways in glaucoma: a unifying concept of disease mechanisms and causative treatment. Eur. J. Pharm. Biopharm. 95:173-181, 2015.

15. Weinreb, R.N., Aung, T., and Medeiros, F.A. The pathophysiology and treatment of glaucoma: a review. JAMA. 311:1901-1911, 2014.

16. Krauss, A.H., Impagnatiello, F., Toris, C.B., Gale, D.C., Prasanna, G., Borghi, V., Chiroli, V., Chong, W.K., Carreiro, S.T., and Ongini, E. Ocular hypotensive activity of BOL-303259-X, a nitric oxide donating prostaglandin F2alpha agonist, in preclinical models. Exp. Eye Res. 93: 250-255, 2011.

17. Toris, C.B., Gabelt, B.T., and Kaufman, P.L. Update on the mechanism of action of topical prostaglandins for intraocular pressure reduction. Surv. Ophthalmol. 53 Suppl 1: S107-S120, 2008.

18. Schachtschabel, U., Lindsey, J.D., and Weinreb, R.N. The mechanism of action of prostaglandins on uveoscleral outflow. Curr. Opin. Ophthalmol. 11:112-115, 2000.

19. Kuo, P.C., and Schroeder, R.A. The emerging multifaceted roles of nitric oxide. Ann. Surg. 221:220-235, 1995.

20. Bryan, N.S., Bian, K., and Murad, F. Discovery of the nitric oxide signaling pathway and targets for drug development. Front. Biosci. (Landmark Ed). 14:1-18, 2009.

21. Culotta, E., Koshland, D.E., Jr. NO news is good news. Science. 258:1862-1865, 1992.

22. Buys, E.S., Potter, L.R., Pasquale, L.R., and Ksander, B.R. Regulation of intraocular pressure by soluble and membrane guanylate cyclases and their role in glaucoma. Front. Mol. Neurosci. 7:38, 2014.

23. Stamer, W.D., Lei, Y., Boussommier-Calleja, A., Overby, D.R., and Ethier, C.R. eNOS, a pressure-dependent regulator of intraocular pressure. Invest. Ophthalmol. Vis. Sci. 52:9438-9444, 2011.

24. Lei, Y., Zhang, X., Song, M., Wu, J., and Sun, X. Aqueous humor outflow physiology in NOS3 knockout mice. Invest. Ophthalmol. Vis. Sci. 56:4891-4898, 2015.

25. Chang, J.Y., Stamer, W.D., Bertrand, J., Read, A.T., Marando, C.M., Ethier, C.R., and Overby, D.R. Role of nitric 
oxide in murine conventional outflow physiology. Am. J. Physiol. Cell Physiol. 309:C205-C214, 2015.

26. Ellis, D.Z., Dismuke, W.M., and Chokshi, B.M. Characterization of soluble guanylate cyclase in NO-induced increases in aqueous humor outflow facility and in the trabecular meshwork. Invest. Ophthalmol. Vis. Sci. 50:1808-1813, 2009.

27. Ellis, D.Z., Sharif, N.A., and Dismuke, W.M. Endogenous regulation of human Schlemm's canal cell volume by nitric oxide signaling. Invest. Ophthalmol. Vis. Sci. 51:58175824, 2010

28. Schneemann, A., Dijkstra, B.G., van den Berg, T.J., Kamphuis, W., and Hoyng, P.F. Nitric oxide/guanylate cyclase pathways and flow in anterior segment perfusion. Graefes Arch. Clin. Exp. Ophthalmol. 240:936-941, 2002.

29. Buys, E.S., Ko, Y.C., Alt, C., Hayton, S.R., Jones, A., Tainsh, L.T., Ren, R., Giani, A., Clerte, M., Abernathy, E., Tainsh, R.E., Oh, D.J., Malhotra, R., Arora, P., de Waard, N., Yu, B., Turcotte, R., Nathan, D., Scherrer-Crosbie, M., Loomis, S.J., Kang, J.H., Lin, C.P., Gong, H., Rhee, D.J., Brouckaert, P., Wiggs, J.L., Gregory, M.S., Pasquale, L.R., Bloch, K.D., and Ksander, B.R. Soluble guanylate cyclase $\alpha 1$-deficient mice: a novel murine model for primary open angle glaucoma. PLoS One. 8:e60156, 2013.

30. Galassi, F., Renieri, G., Sodi, A., Ucci, F., Vannozzi, L., and Masini, E. Nitric oxide proxies and ocular perfusion pressure in primary open angle glaucoma. Br. J. Ophthalmol. 88:757-760, 2004.

31. Doganay, S., Evereklioglu, C., Turkoz, Y., and Er, H. Decreased nitric oxide production in primary open-angle glaucoma. Eur. J. Ophthalmol. 12:44-48, 2002.

32. Nathanson, J.A., and McKee, M. Alterations of ocular nitric oxide synthase in human glaucoma. Invest. Ophthalmol. Vis. Sci. 36:1774-1784, 1995.

33. Javadiyan, S., Burdon, K.P., Whiting, M.J., Abhary, S., Straga, T., Hewitt, A.W., Mills, R.A., and Craig, J.E. Elevation of serum asymmetrical and symmetrical dimethylarginine in patients with advanced glaucoma. Invest. Ophthalmol. Vis. Sci. 53:1923-1927, 2012.

34. Tunny, T.J., Richardson, K.A., and Clark, C.V. Association study of the $5^{\prime}$ flanking regions of endothelial-nitric oxide synthase and endothelin-1 genes in familial primary openangle glaucoma. Clin. Exp. Pharmacol. Physiol. 25:26-29, 1998.

35. Kang, J.H., Wiggs, J.L., Rosner, B.A., Hankinson, S.E., Abdrabou, W., Fan, B.J., Haines, J., and Pasquale, L.R. Endothelial nitric oxide synthase gene variants and primary open-angle glaucoma: interactions with sex and postmenopausal hormone use. Invest. Ophthalmol. Vis. Sci. 51:971979, 2010.

36. Kang, J.H., Wiggs, J.L., Haines, J., Abdrabou, W., and Pasquale, L.R. Reproductive factors and NOS3 variant interactions in primary open-angle glaucoma. Mol. Vis. 17: 2544-2551, 2011.

37. Kang, J.H., Willett, W.C., Rosner, B.A., Buys, E., Wiggs, J.L., and Pasquale, L.R. Association of dietary nitrate intake with primary open-angle glaucoma: a prospective analysis from the nurses' health study and health professionals followup study. JAMA Ophthalmol. 134:294-303, 2016.

38. Pasquale, L.R. Vascular and autonomic dysregulation in primary open-angle glaucoma. Curr. Opin. Ophthalmol. 27: 94-101, 2016.

39. Dismuke, W.M., Liang, J., Overby, D.R., and Stamer, W.D. Concentration-related effects of nitric oxide and endothelin-1 on human trabecular meshwork cell contractility. Exp. Eye Res. 120:28-35, 2013.
40. Wiederholt, M., Sturm, A., and Lepple-Wienhues, A. Relaxation of trabecular meshwork and ciliary muscle by release of nitric oxide. Invest. Ophthalmol. Vis. Sci. 35: 2515-2520, 1994.

41. Nathanson, J.A. Nitrovasodilators as a new class of ocular hypotensive agents. J. Pharmacol. Exp. Ther. 260:956-965, 1992.

42. Kotikoski, H., Vapaatalo, H., and Oksala, O. Nitric oxide and cyclic GMP enhance aqueous humor outflow facility in rabbits. Curr. Eye Res. 26:119-123, 2003.

43. Schuman, J.S., Erickson, K., and Nathanson, J.A. Nitrovasodilator effects on intraocular pressure and outflow facility in monkeys. Exp. Eye Res. 58:99-105, 1994.

44. Heyne, G.W., Kiland, J.A., Kaufman, P.L., and Gabelt, B.T. Effect of nitric oxide on anterior segment physiology in monkeys. Invest. Ophthalmol. Vis. Sci. 54:5103-5110, 2013.

45. Dismuke, W.M., Mbadugha, C.C., and Ellis, D.Z. NOinduced regulation of human trabecular meshwork cell volume and aqueous humor outflow facility involve the $\mathrm{BKCa}$ ion channel. Am. J. Physiol. Cell Physiol. 294:C1378C1386, 2008.

46. Kotikoski, H., Alajuuma, P., Moilanen, E., Salmenpera, P., Oksala, O., Laippala, P., and Vapaatalo, H. Comparison of nitric oxide donors in lowering intraocular pressure in rabbits: role of cyclic GMP. J. Ocul. Pharmacol. Ther. 18:1123, 2002.

47. Thoonen, R., Sips, P.Y., Bloch, K.D., and Buys, E.S. Pathophysiology of hypertension in the absence of nitric oxide/ cyclic GMP signaling. Curr. Hypertens. Rep. 15:47-58, 2013.

48. Ashpole, N.E., Overby, D.R., Ethier, C.R., and Stamer, W.D. Shear stress-triggered nitric oxide release from Schlemm's canal cells. Invest. Ophthalmol. Vis. Sci. 55: 8067-8076, 2014.

49. Becquet, F., Courtois, Y., and Goureau, O. Nitric oxide in the eye: multifaceted roles and diverse outcomes. Surv. Ophthalmol. 42:71-82, 1997.

50. Cavet, M.E., Vittitow, J.L., Impagnatiello, F., Ongini, E., and Bastia, E. Nitric oxide (NO): an emerging target for the treatment of glaucoma. Invest. Ophthalmol. Vis. Sci. 55:5005-5015, 2014.

51. Cavet, M.E., Vollmer, T.R., Harrington, K.L., VanDerMeid, K., and Richardson, M.E. Regulation of endothelin1-induced trabecular meshwork cell contractility by latanoprostene bunod. Invest. Ophthalmol. Vis. Sci. 56: 4108-4116, 2015.

52. Pattabiraman, P.P., Pecen, P.E., and Rao, P.V. MRP4mediated regulation of intracellular cAMP and cGMP levels in trabecular meshwork cells and homeostasis of intraocular pressure. Invest. Ophthalmol. Vis. Sci. 54:16361649, 2013.

53. Kaufman, P.L. Enhancing trabecular outflow by disrupting the actin cytoskeleton, increasing uveoscleral outflow with prostaglandins, and understanding the pathophysiology of presbyopia interrogating Mother Nature: asking why, asking how, recognizing the signs, following the trail. Exp. Eye Res. 86:3-17, 2008.

54. Brubaker, R.F. Targeting outflow facility in glaucoma management. Surv. Ophthalmol. 48 Suppl 1:S17-S20, 2003.

55. Liu, J.H., Slight, J.R., Vittitow, J.L., Scassellati Sforzolini, B., and Weinreb, R.N. Efficacy of latanoprostene bunod $0.024 \%$ compared with timolol $0.5 \%$ in lowering intraocular pressure over 24 hours. Am. J. Ophthalmol. 169:249257, 2016.

56. Araie, M., Sforzolini, B.S., Vittitow, J., and Weinreb, R.N. Evaluation of the effect of latanoprostene bunod ophthalmic 
solution, $0.024 \%$ in lowering intraocular pressure over $24 \mathrm{~h}$ in healthy Japanese subjects. Adv. Ther. 32:1128-1139, 2015.

57. Levy, P.D., Laribi, S., and Mebazaa, A. Vasodilators in acute heart failure: review of the latest studies. Curr. Emerg. Hosp. Med. Rep. 2:126-132, 2014.

58. Weinreb, R.N., Realini, T., and Varma, R. Latanoprostene bunod, a dual-acting nitric oxide donating prostaglandin analog for lowering of intraocular pressure. US Ophthalmic Rev. 9:80-87, 2016.

59. Kaufman, P.L. Latanoprostene bunod ophthalmic solution $0.024 \%$ for IOP lowering in glaucoma and ocular hypertension. Expert Opin. Pharmacother. 18:433-444, 2017.

60. Lee, V.H., Morimoto, K.W., Stratford, R.E., Jr. Esterase distribution in the rabbit cornea and its implications in ocular drug bioavailability. Biopharm. Drug Dispos. 3:291300, 1982.

61. Thomas, D.D., Liu, X., Kantrow, S.P., Lancaster, J.R., Jr. The biological lifetime of nitric oxide: implications for the perivascular dynamics of $\mathrm{NO}$ and O2. Proc. Natl. Acad. Sci. U S A. 98:355-360, 2001.

62. Sager, G. Cyclic GMP transporters. Neurochem. Int. 45: 865-873, 2004.

63. Vadlapatla, R.K., Vadlapudi, A.D., Pal, D., and Mitra, A.K. Role of membrane transporters and metabolizing enzymes in ocular drug delivery. Curr. Drug Metab. 15:680-693, 2014.

64. Govoni, M., Casagrande, S., Maucci, R., Chiroli, V., and Tocchetti, P. In vitro metabolism of (nitrooxy)butyl ester nitric oxide-releasing compounds: comparison with glyceryl trinitrate. J. Pharmacol. Exp. Ther. 317:752-761, 2006.

65. Saeki, T., Tsuruga, H., Aihara, M., Araie, M., and Rittenhouse, K. Dose-response profile of PF-03187207 (PF-207) and peak IOP lowering response following single topical administration to FP receptor knockout mice vs. wild type mice. Invest. Ophthalmol. Vis. Sci. 50:4064, 2009.

66. Cuppoletti, J., Malinowska, D.H., Tewari, K.P., Chakrabarti, J., and Ueno, R. Unoprostone isopropyl and metabolite M1 activate $\mathrm{BK}$ channels and prevent ET-1-induced $\left[\mathrm{Ca}^{2+}\right]_{\mathrm{i}}$ increases in human trabecular meshwork and smooth muscle. Invest. Ophthalmol. Vis. Sci. 53:5178-5189, 2012.

67. Choritz, L., Machert, M., and Thieme, H. Correlation of endothelin-1 concentration in aqueous humor with intraocular pressure in primary open angle and pseudoexfoliation glaucoma. Invest. Ophthalmol. Vis. Sci. 53:7336-7342, 2012.

68. Rosenthal, R., and Fromm, M. Endothelin antagonism as an active principle for glaucoma therapy. Br. J. Pharmacol. 162:806-816, 2011.

69. Wang, J.W., Woodward, D.F., and Stamer, W.D. Differential effects of prostaglandin E2-sensitive receptors on contractility of human ocular cells that regulate conventional outflow. Invest. Ophthalmol. Vis. Sci. 54:4782-4790, 2013.

70. Ota, T., Aihara, M., Narumiya, S., and Araie, M. The effects of prostaglandin analogues on IOP in prostanoid FPreceptor-deficient mice. Invest. Ophthalmol. Vis. Sci. 46: 4159-4163, 2005.

71. Crowston, J.G., Lindsey, J.D., Aihara, M., and Weinreb, R.N. Effect of latanoprost on intraocular pressure in mice lacking the prostaglandin FP receptor. Invest. Ophthalmol. Vis. Sci. 45:3555-3559, 2004.

72. Orihashi, M., Shima, Y., Tsuneki, H., and Kimura, I. Potent reduction of intraocular pressure by nipradilol plus latanoprost in ocular hypertensive rabbits. Biol. Pharm. Bull. 28:65-68, 2005.

73. Woodward, D.F., Burke, J.A., Williams, L.S., Palmer, B.P., Wheeler, L.A., Woldemussie, E., Ruiz, G., and Chen, J. Prostaglandin F2 alpha effects on intraocular pressure negatively correlate with FP-receptor stimulation. Invest. Ophthalmol. Vis. Sci. 30:1838-1842, 1989.

74. Weinreb, R.N., Ong, T., Scassellati Sforzolini, B., Vittitow, J.L., Singh, K., and Kaufman, P.L. A randomised, controlled comparison of latanoprostene bunod and latanoprost $0.005 \%$ in the treatment of ocular hypertension and open angle glaucoma: the VOYAGER study. Br. J. Ophthalmol. 99:738-745, 2014.

75. Eveleth, D., Starita, C., and Tressler, C. A 4-week, doseranging study comparing the efficacy, safety and tolerability of latanoprost 75,100 and $125 \mu \mathrm{g} / \mathrm{mL}$ to latanoprost $50 \mu \mathrm{g} / \mathrm{mL}$ (xalatan) in the treatment of primary open-angle glaucoma and ocular hypertension. BMC Ophthalmol. 12:9, 2013.

76. Kawase, K., Vittitow, J.L., Weinreb, R.N., Araie, M. Longterm safety and efficacy of latanoprostene bunod $0.024 \%$ in Japanese subjects with open-angle glaucoma or ocular hypertension: The JUPITER study. Adv. Ther. 33:1612-1627, 2016.

Received: January 9, 2017

Accepted: March 26, 2017

Address correspondence to: Megan Cavet, $P h D$ Bausch + Lomb

1400 North Goodman Street Rochester, NY 14609

E-mail: megan.cavet@bausch.com 